\title{
Correction to: Accelerated reproduction of 2-D periodic waves
}

\section{Dmitry Chalikov ${ }^{1,2}$}

Published online: 9 March 2021

(C) Springer-Verlag GmbH Germany, part of Springer Nature 2021

\section{Correction to: Ocean Dynamics (2021) 71:309-322 https://doi.org/10.1007/s10236-020-01435-8}

The article "Accelerated reproduction of 2-D periodic waves", written by Chalikov D., was originally published online on 29 January 2021 with Open Access under a Creative Commons Attribution 4.0 International License.
After publication in volume 71, issue 3, page 309-322 the author(s) decided to cancel the Open Access. Therefore, the copyright of the article has been changed on 30 January 2021 to (C) Springer-Verlag GmbH, DE part of Springer Nature 2021 with all rights reserved.

The original article has been corrected.

The online version of the original article can be found at https://oi.org/ 10.1007/s10236-020-01435-8

\footnotetext{
Dmitry Chalikov

dmitry-chalikov@yandex.ru

1 Shirshov Institute of Oceanology RAS, Moscow 199053, Russia

2 University of Melbourne, Melbourne, Victoria 3010, Australia
} 